\title{
Application of Artificial Neural Network for Analysis of Triangular Plate with Hole Considering Different Geometrical and Loading Parameters
}

\author{
Saket Rusia, Krishna Kant Pathak \\ Department of Civil and Environmental Engineering, National Institute of Technical Teachers' Training and \\ Research, Bhopal, India \\ Email: saketrusia123@gmail.com, kkpathak@nitttrbpl.ac.in
}

Received 6 February 2016; accepted 26 February 2016; published 29 February 2016

Copyright (C) 2016 by authors and Scientific Research Publishing Inc.

This work is licensed under the Creative Commons Attribution International License (CC BY). http://creativecommons.org/licenses/by/4.0/

c) (7) Open Access

\begin{abstract}
In this study, Artificial Neural Network has been employed for analysis of triangular plate with different geometrical and loading parameters. Plates, having different sizes of concentric holes are analyzed. Finite element analysis for $\mathbf{8 1}$ cases is carried out using ANSYS Workbench 15.0 software. Using these data of FEM analysis an Artificial Neural Network has been trained. The successfully trained network is further used for analysis of four new cases which are also validated by using ANSYS Workbench 15.0 software.
\end{abstract}

Keywords

Artificial Neural Networks, Finite Element Analysis, Triangular Plate, ANSYS

\section{Introduction}

Regardless of the powerful analysis software now available those allow us to find out the numerical solution of various problems, including problems of structural analysis, the development of methods of approximate solution which would provide solutions in the form of simple analytic expressions is very important. One of the methods is artificial neural network also known as ANN. These are a functional abstraction of the biologic neural structures of the central nervous system.

Scientists have long been inspired by the human brain. In 1943, Warren S. McCulloch, a neuroscientist, and Walter Pitts [1], a logician, developed the first conceptual model of an Artificial Neural Network. In their paper, 
"A logical calculus of the ideas imminent in nervous activity”, they described the concept of a neuron, a single cell living in a network of cells that receives inputs, processes those inputs, and generates an output. Their work, and the work of many scientists and researchers that followed, did not mean to accurately describe how the biological brain works. Rather, an Artificial Neural Network was designed as a computational model based on the brain to solve certain kinds of problems.

ANNs are powerful pattern recognizers and classifiers. Garrett [2] has given an interesting engineering definition of the ANN as: "a computational mechanism able to acquire, represent, and compute mapping from one multivariate space of information to another, given a set of data representing that mapping”. Their computing abilities have been proven in the fields of prediction and estimation, pattern recognition, and optimization. They are suitable particularly for problems too complex to be modeled and solved by classical mathematics and traditional procedures. Neural networks can be hardware (neurons are represented by physical components) or software based (computer models), and can use a variety of topologies and learning algorithms. Neural networks have been used for various structural analysis like fully stressed design of trusses, buckling behavior of plates, stress concentration factor analysis for membranes etc.

In Figure 1, an Artificial Neural Network consisting of an input layer with three neurons, one hidden layer with four neurons, and an output layer with two neurons is shown. There would be a state function and transfer function like summation function, sigmoid squashing function respectively. Here, a training algorithm is needed that can be a back-propagation algorithm. Neurons are the processing elements of network. Neuron consists of a set of weighted input connections, a bias input, a state function, a nonlinear transfer function, and an output. Figure 2 shows the structure of a neuron.

P. Emmanuel Nicholas et al. [3] proposed a novel approach to study neural network based buckling strength prediction of laminated composite plate with central cut-out. The laminated composite plates with holes analyzed using finite element analysis by optimizing the parameters like thickness, orientation, material and the stacking sequence to obtain the desired characteristics for these structures. They showed that using finite element analysis makes the process a more tedious job and thus proposed to construct the Artificial Neural Network to predict the buckling behavior of the composite plate. Hojjat Adeli [4] presented the first journal article on neural network application in civil/structural engineering in 1989.
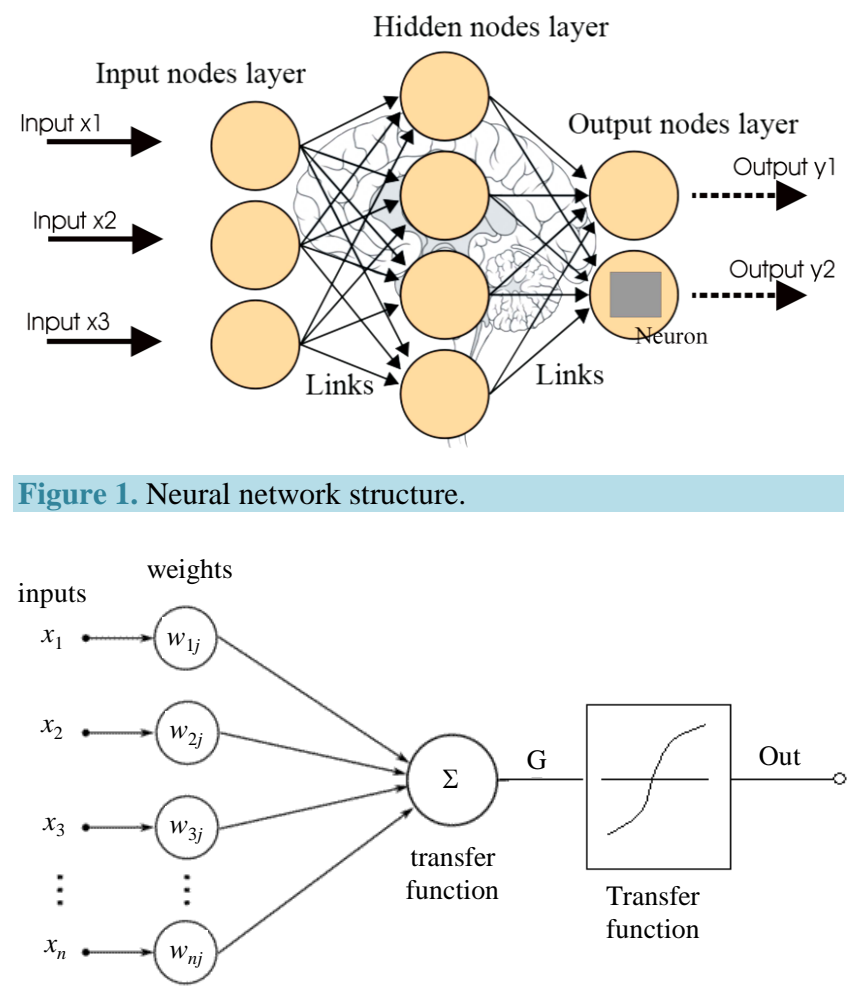

Figure 2. Structure of a neuron. 
In many previous research papers, membrane with holes or cutouts analysed using finite element software like ANSYS [5], also stress field around circular holes in plates with arbitrary thickness has been studied but most of the time loading considered is to be in plane loading, However, it seems to be difficult to locate a work that quantifies the use of ANNs for analysis of equivalent stress, strain and directional deformation in a triangular plate subjected to vertical surface pressure without performing finite element analysis. The Artificial Neural Network is used as an alternative analysis tool to analyze plates with hole since it can handle uncertainty through the probability method. In some of the following research papers finite element analysis has been performed for plates and membranes with cut-outs. Zuxing Pan, Yuansheng Cheng and Jun Liu [6], dealt with a complex variable method and proposed stress functions to obtain the solution for stress distribution around rectangular hole in finite plate subjected to uniaxial tension. They analyzed effect of hole sizes, hole orientation and plate's aspect ratio on stress distribution. Jeom Kee Paik [7] examined the ultimate strength of metallic plates with central circular cut-out under shear loading. The influence of boundary conditions on the buckling load for rectangular plates of various cut-out shape, length/thickness ratio, and ply orientation was examined by Buket Okutan Baba [8]. Boundary conditions considered and their various combinations were clamped, and pinned. The plates were subjected to in-plane compression load. The results of experimentation were validated using numerical analysis by ANSYS. A.V Singh, U.K Paul [9], presented the results of their study which was based on generalized work-energy method for rectangular plates with circular cut-out. Optimum design of holes and notches by considering fatigue life was presented by Hwai Chung Wu, and Bin Mu [10]. V.G. Ukadgaonker, and D.K.N. Rao [11] gave a general solution for bending of symmetric laminates with holes considering any shape of hole in symmetric laminates subjected to remotely apply bending or twisting moments. Moments around circular, elliptical, triangular, square, rectangular and several irregular shaped holes in cross-ply and angle ply symmetric laminates are obtained. Hsuan-Teh Hu, and Bor-Horng Lin [12] studied the buckling resistance of symmetrically laminated plates with a given material system subjected to uniaxial compression. The research was done with plates having different plate thicknesses, aspect ratios, central circular cut-outs and different end conditions.

In this study, Artificial Neural Network has been employed for analysis of maximum equivalent von Mises stress, strain and directional deformation in equilateral triangular plate with different geometrical and loading patterns. Plates, having different size concentric holes are analyzed. Finite element analysis for 81 cases is carried out using ANSYS Workbench 15.0 software. Using these data of FEM analysis an Artificial Neural Network has been trained. The successfully trained network is further used for analysis of five new cases which are also validated using ANSYS Workbench 15.0 software.

\section{Structural Modelling and Analysis}

Modeling, meshing and analysis contours of plate are shown in Figure 3. Plate is a polygon of three sides having concentric hole. Size of edges of plate, thickness, size of hole diameter and loading pressure are varying parameters. In Table 1, isotropic elastic constants values are shown, those were used given to as elemental properties. Other, in use entities for finite element modeling is provided in Table 2. In total 81 cases are generated, and these are stated in Table 3.

Geometry of the plates are created using ANSYS workbench 15.0 geometry tool, design modeler and then analysed using ANSYS mechanical or multi-physics too. In these models, fixed edge support condition is provided. Varying loading pressure is acting in $-\mathrm{z}$ direction where plates are lying in $\mathrm{X}-\mathrm{Y}$ plane.

In Figure 3, A is showing the model view, B is the meshed structure, in C, Loading has been shown and in D, $\mathrm{E}, \mathrm{F}$, contour of variation in maximum equivalent von Mises stress, strain and directional deformation are shown respectively.

\section{Finite Element Analysis}

Finite element analysis has been performed using ANSYS Workbench 15.0 and results for following parameters are recorded,

1) Maximum Equivalent von Mises Stress

2) Maximum Equivalent von Mises Strain

3) Directional Deformation in Z-Direction

Output results are tabulated in Table 4. These values have been used as training data for Artificial Neural Network, in the next section. 

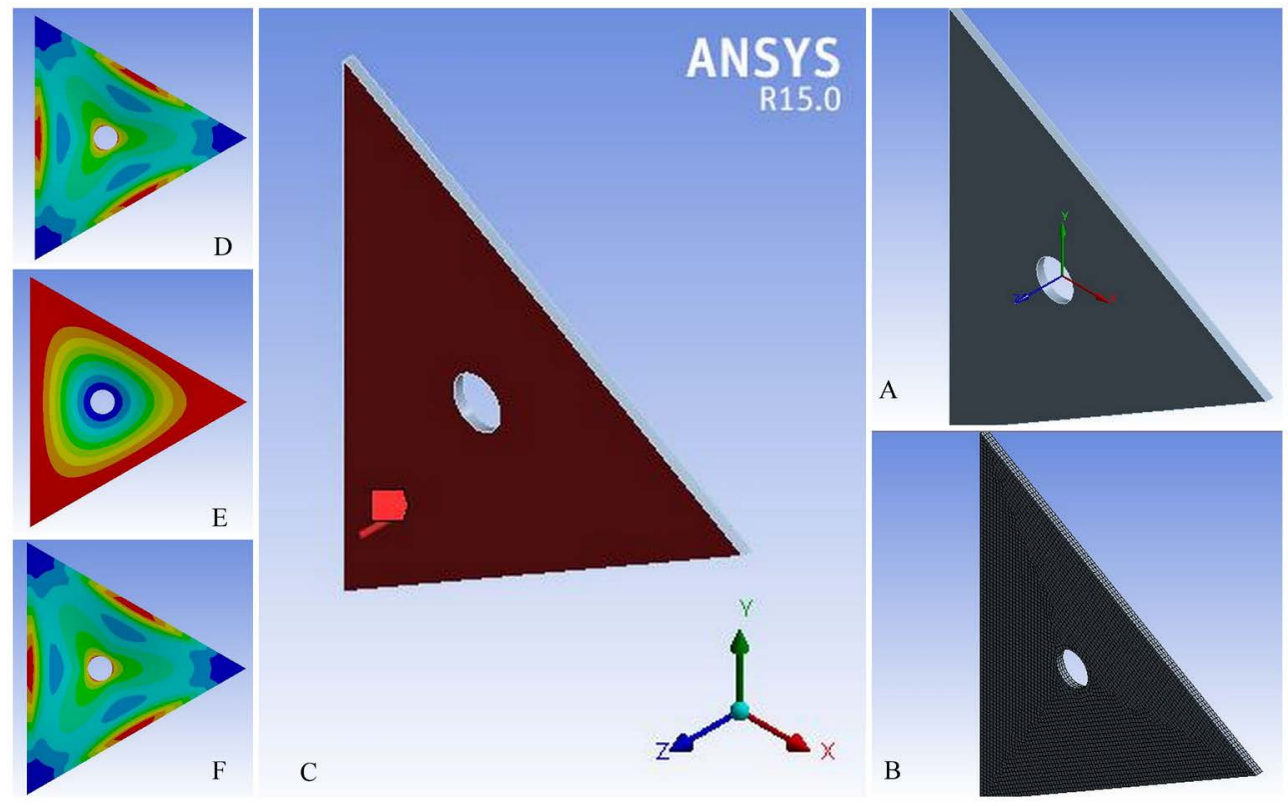

Figure 3. Modeling, meshing \& analyses of plate.

Table 1. Isotropic elastic constants.

\begin{tabular}{cccc}
\hline $\begin{array}{c}\text { Young's Modulus } \\
(\mathrm{MPa})\end{array}$ & Poisson's Ratio & $\begin{array}{c}\text { Bulk Modulus } \\
(\mathrm{Pa})\end{array}$ & $\begin{array}{c}\text { Shear Modulus } \\
(\mathrm{MPa})\end{array}$ \\
\hline $2 \mathrm{E}+5$ & 0.3 & $1.6667 \mathrm{E}+5$ & $7.692 \mathrm{E}+4$ \\
\hline
\end{tabular}

Table 2. Entities for finite element modeling.

\begin{tabular}{ccc}
\hline Sr. No. & Parameters & Value \\
\hline 1 & Material & Structural steel \\
2 & Polygon & Three sided equilateral triangle \\
3 & Hole & Single and concentric \\
4 & Support condition & All fixed edges \\
5 & Loading & Surface pressure in -Z direction \\
6 & Meshing element & Eight noded hexahedral element \\
7 & Meshing inflation & Automatic (program controlled) \\
8 & Relevance & 0 \\
9 & Relevance center & Fine \\
10 & Meshing smoothing & Medium \\
11 & Span angle center & Fine \\
\hline
\end{tabular}

\section{Application of Neural Network}

The input, output data given in Table 3 and Table 4 are used for training of the neural network. A 4-6-3 size back propagation neural has been trained. The input parameters are edge dimension, hole diameter, thickness of plate and pressure applied and output parameters are maximum equivalent von Mises stress, maximum equivalent von Mises strain and directional deformation in Z-direction. For ANN, an in-house developed software has been used. The error tolerance is kept 0.005 . It took 1996082 epochs to converge to this tolerance. Thus trained network is used for fully analysis of four new cases of model plates, given in Table 5 . 
Table 3. Input for finite element models.

\begin{tabular}{|c|c|c|c|c|c|c|c|c|c|}
\hline \multirow[b]{2}{*}{ Sr. No. } & \multicolumn{4}{|c|}{ Input for ANSYS } & \multirow[b]{2}{*}{ Sr. No. } & \multicolumn{4}{|c|}{ Input for ANSYS } \\
\hline & $\begin{array}{c}\text { Edge } \\
\text { Dimension } \\
(\mathrm{mm})\end{array}$ & $\begin{array}{l}\text { Hole Dia. } \\
\quad(\mathrm{mm})\end{array}$ & $\begin{array}{c}\text { Thickness } \\
\text { of Plate } \\
\text { (mm) }\end{array}$ & $\begin{array}{c}\text { Pressure } \\
\text { Applied } \\
(\mathrm{MPa})\end{array}$ & & $\begin{array}{c}\text { Edge } \\
\text { Dimension } \\
(\mathrm{mm})\end{array}$ & $\begin{array}{l}\text { Hole Dia. } \\
\text { (mm) }\end{array}$ & $\begin{array}{l}\text { Thickness } \\
\text { of Plate } \\
\text { (mm) }\end{array}$ & $\begin{array}{c}\text { Pressure } \\
\text { Applied } \\
\text { (MPa) }\end{array}$ \\
\hline 1 & 500 & 50 & 10 & 0.3 & 42 & 750 & 75 & 20 & 0.7 \\
\hline 2 & 500 & 50 & 10 & 0.5 & 43 & 750 & 75 & 30 & 0.3 \\
\hline 3 & 500 & 50 & 10 & 0.7 & 44 & 750 & 75 & 30 & 0.5 \\
\hline 4 & 500 & 50 & 20 & 0.3 & 45 & 750 & 75 & 30 & 0.7 \\
\hline 5 & 500 & 50 & 20 & 0.5 & 46 & 750 & 100 & 10 & 0.3 \\
\hline 6 & 500 & 50 & 20 & 0.7 & 47 & 750 & 100 & 10 & 0.5 \\
\hline 7 & 500 & 50 & 30 & 0.3 & 48 & 750 & 100 & 10 & 0.7 \\
\hline 8 & 500 & 50 & 30 & 0.5 & 49 & 750 & 100 & 20 & 0.3 \\
\hline 9 & 500 & 50 & 30 & 0.7 & 50 & 750 & 100 & 20 & 0.5 \\
\hline 10 & 500 & 75 & 10 & 0.3 & 51 & 750 & 100 & 20 & 0.7 \\
\hline 11 & 500 & 75 & 10 & 0.5 & 52 & 750 & 100 & 30 & 0.3 \\
\hline 12 & 500 & 75 & 10 & 0.7 & 53 & 750 & 100 & 30 & 0.5 \\
\hline 13 & 500 & 75 & 20 & 0.3 & 54 & 750 & 100 & 30 & 0.7 \\
\hline 14 & 500 & 75 & 20 & 0.5 & 55 & 1000 & 50 & 10 & 0.3 \\
\hline 15 & 500 & 75 & 20 & 0.7 & 56 & 1000 & 50 & 10 & 0.5 \\
\hline 16 & 500 & 75 & 30 & 0.3 & 57 & 1000 & 50 & 10 & 0.7 \\
\hline 17 & 500 & 75 & 30 & 0.5 & 58 & 1000 & 50 & 20 & 0.3 \\
\hline 18 & 500 & 75 & 30 & 0.7 & 59 & 1000 & 50 & 20 & 0.5 \\
\hline 19 & 500 & 100 & 10 & 0.3 & 60 & 1000 & 50 & 20 & 0.7 \\
\hline 20 & 500 & 100 & 10 & 0.5 & 61 & 1000 & 50 & 30 & 0.3 \\
\hline 21 & 500 & 100 & 10 & 0.7 & 62 & 1000 & 50 & 30 & 0.5 \\
\hline 22 & 500 & 100 & 20 & 0.3 & 63 & 1000 & 50 & 30 & 0.7 \\
\hline 23 & 500 & 100 & 20 & 0.5 & 64 & 1000 & 75 & 10 & 0.3 \\
\hline 24 & 500 & 100 & 20 & 0.7 & 65 & 1000 & 75 & 10 & 0.5 \\
\hline 25 & 500 & 100 & 30 & 0.3 & 66 & 1000 & 75 & 10 & 0.7 \\
\hline 26 & 500 & 100 & 30 & 0.5 & 67 & 1000 & 75 & 20 & 0.3 \\
\hline 27 & 500 & 100 & 30 & 0.7 & 68 & 1000 & 75 & 20 & 0.5 \\
\hline 28 & 750 & 50 & 10 & 0.3 & 69 & 1000 & 75 & 20 & 0.7 \\
\hline 29 & 750 & 50 & 10 & 0.5 & 70 & 1000 & 75 & 30 & 0.3 \\
\hline 30 & 750 & 50 & 10 & 0.7 & 71 & 1000 & 75 & 30 & 0.5 \\
\hline 31 & 750 & 50 & 20 & 0.3 & 72 & 1000 & 75 & 30 & 0.7 \\
\hline 32 & 750 & 50 & 20 & 0.5 & 73 & 1000 & 100 & 10 & 0.3 \\
\hline 33 & 750 & 50 & 20 & 0.7 & 74 & 1000 & 100 & 10 & 0.5 \\
\hline 34 & 750 & 50 & 30 & 0.3 & 75 & 1000 & 100 & 10 & 0.7 \\
\hline 35 & 750 & 50 & 30 & 0.5 & 76 & 1000 & 100 & 20 & 0.3 \\
\hline 36 & 750 & 50 & 30 & 0.7 & 77 & 1000 & 100 & 20 & 0.5 \\
\hline 37 & 750 & 75 & 10 & 0.3 & 78 & 1000 & 100 & 20 & 0.7 \\
\hline 38 & 750 & 75 & 10 & 0.5 & 79 & 1000 & 100 & 30 & 0.3 \\
\hline 39 & 750 & 75 & 10 & 0.7 & 80 & 1000 & 100 & 30 & 0.5 \\
\hline 40 & 750 & 75 & 20 & 0.3 & 81 & 1000 & 100 & 30 & 0.7 \\
\hline 41 & 750 & 75 & 20 & 0.5 & & & & & \\
\hline
\end{tabular}


Table 4. Data recorded as output of finite element analyses.

\begin{tabular}{|c|c|c|c|c|c|c|c|}
\hline \multirow[b]{2}{*}{ Sr. No. } & \multicolumn{3}{|c|}{ Output from ANSYS } & \multirow[b]{2}{*}{ Sr. No. } & \multicolumn{3}{|c|}{ Output from ANSYS } \\
\hline & $\begin{array}{l}\text { Maximum } \\
\text { Equivalent von } \\
\text { Mises Stress } \\
(\mathrm{MPa})\end{array}$ & $\begin{array}{l}\text { Maximum } \\
\text { Equivalent von } \\
\text { Mises Strain } \\
* 10^{-5}(\mathrm{~mm} / \mathrm{mm})\end{array}$ & $\begin{array}{l}\text { Maximum } \\
\text { Directional (-z) } \\
\text { Deformation } \\
\quad(\mathrm{mm})\end{array}$ & & $\begin{array}{c}\text { Maximum } \\
\text { Equivalent von } \\
\text { Mises Stress } \\
(\mathrm{MPa})\end{array}$ & $\begin{array}{l}\text { Maximum } \\
\text { Equivalent von } \\
\text { Mises Strain } \\
* 10^{-5}(\mathrm{~mm} / \mathrm{mm})\end{array}$ & $\begin{array}{l}\text { Maximum } \\
\text { Directional (-z) } \\
\text { Deformation } \\
(\mathrm{mm})\end{array}$ \\
\hline 1 & 66.202 & 33.261 & 0.18405 & 42 & 87.259 & 43.827 & 0.27533 \\
\hline 2 & 110.34 & 55.436 & 0.30674 & 43 & 17.679 & 8.8397 & 0.036354 \\
\hline 3 & 154.47 & 77.61 & 0.42944 & 44 & 29.466 & 14.733 & 0.060589 \\
\hline 4 & 17.685 & 8.842 & 0.0242 & 45 & 41.252 & 20.626 & 0.084825 \\
\hline 5 & 29.475 & 14.737 & 0.040393 & 46 & 162.05 & 81.025 & 0.88067 \\
\hline 6 & 41.264 & 20.632 & 0.056551 & 47 & 270.08 & 135.04 & 1.4678 \\
\hline 7 & 9.0018 & 4.5009 & 0.00778 & 48 & 378.12 & 189.06 & 2.0549 \\
\hline 8 & 15.003 & 7.5015 & 0.012967 & 49 & 39.943 & 19.534 & 0.11334 \\
\hline 9 & 21.004 & 10.502 & 0.018154 & 50 & 64.905 & 32.557 & 0.18889 \\
\hline 10 & 67.227 & 33.753 & 0.1706 & 51 & 90.867 & 45.579 & 0.26445 \\
\hline 11 & 112.04 & 56.256 & 0.28433 & 52 & 17.486 & 8.743 & 0.034888 \\
\hline 12 & 156.86 & 78.758 & 0.39806 & 53 & 29.143 & 14.572 & 0.058146 \\
\hline 13 & 17.195 & 8.5975 & 0.02245 & 54 & 40.801 & 20.4 & 0.081404 \\
\hline 14 & 28.658 & 14.329 & 0.037417 & 55 & 283.38 & 141.69 & 2.8552 \\
\hline 15 & 40.122 & 20.061 & 0.052384 & 56 & 472.3 & 236.15 & 4.7587 \\
\hline 16 & 8.7944 & 4.3972 & 0.007203 & 57 & 661.22 & 330.61 & 6.6622 \\
\hline 17 & 14.657 & 7.3286 & 0.012005 & 58 & 71.716 & 35.858 & 0.36461 \\
\hline 18 & 20.52 & 10.26 & 0.016868 & 59 & 119.53 & 59.764 & 0.60768 \\
\hline 19 & 62.198 & 31.23 & 0.14494 & 60 & 167.34 & 83.669 & 0.85075 \\
\hline 20 & 103.66 & 52.05 & 0.24157 & 61 & 32.137 & 16.069 & 0.11049 \\
\hline 21 & 145.13 & 72.869 & 0.3382 & 62 & 53.562 & 26.781 & 0.18415 \\
\hline 22 & 16.042 & 8.0209 & 0.019119 & 63 & 74.987 & 37.494 & 0.25781 \\
\hline 23 & 26.736 & 13.368 & 0.031865 & 64 & 281.18 & 140.59 & 2.8977 \\
\hline 24 & 37.431 & 18.715 & 0.044611 & 65 & 468.64 & 234.32 & 4.8296 \\
\hline 25 & 8.2377 & 4.1189 & 0.006158 & 66 & 656.09 & 328.04 & 6.7614 \\
\hline 26 & 13.73 & 6.8648 & 0.010262 & 67 & 68.241 & 34.121 & 0.36989 \\
\hline 27 & 19.221 & 9.6107 & 0.014367 & 68 & 113.74 & 53.868 & 0.61648 \\
\hline 28 & 152.1 & 76.054 & 0.90679 & 69 & 159.23 & 79.615 & 0.86307 \\
\hline 29 & 253.51 & 126.76 & 1.5113 & 70 & 30.622 & 15.311 & 0.11199 \\
\hline 30 & 354.91 & 177.46 & 2.1158 & 71 & 51.036 & 25.518 & 0.18666 \\
\hline 31 & 39.871 & 19.937 & 0.11829 & 72 & 71.45 & 35.726 & 0.26132 \\
\hline 32 & 66.452 & 33.228 & 0.19714 & 73 & 278.23 & 139.12 & 2.8834 \\
\hline 33 & 93.033 & 46.519 & 0.276 & 74 & 463.72 & 231.86 & 4.8057 \\
\hline 34 & 17.929 & 8.9651 & 0.036494 & 75 & 649.21 & 324.6 & 6.728 \\
\hline 35 & 29.882 & 14.942 & 0.060824 & 76 & 65.935 & 33.129 & 0.36806 \\
\hline 36 & 41.835 & 20.919 & 0.085153 & 77 & 109.89 & 55.215 & 0.61343 \\
\hline 37 & 156.9 & 78.45 & 0.91551 & 78 & 153.85 & 77.301 & 0.8588 \\
\hline 38 & 261.5 & 130.75 & 1.5258 & 79 & 29.562 & 14.844 & 0.11137 \\
\hline 39 & 366.1 & 18.305 & 2.1362 & 80 & 49.27 & 24.739 & 0.18562 \\
\hline 40 & 37.397 & 18.785 & 0.118 & 81 & 69.978 & 34.635 & 0.25987 \\
\hline 41 & 62.328 & 31.305 & 0.19666 & & & & \\
\hline
\end{tabular}


Validation of results has been performed in Table 6, also percentage (\%) variation is carried out between the analysed parameters Artificial Neural Network and ANSYS Workbench. Graphical representation of analysed parameters for new cases model plates are shown in Figure 4, Figure 6, Figure 8 and percentage variation are shown in Figure 5, Figure 7, and Figure 9. It can be observed that averages of absolute positive errors are 3.85, 4.2, and 3.98 for maximum equivalent von Mises stress, maximum equivalent von Mises strain and directional deformation in -Z direction respectively which are small values. Thus it has been proved that the use of Artificial Neural Network can avoid the lengthy and tedious complex modeling and analysis using costly FEM software.

Furthermore, correlation analysis of ANSYS and ANN results have been also carried out and shown in Figures 10-12.

These regression maps are between ANSYS as observed values and ANN as predicted values. The more variance that is accounted for by the regression model the closer the data points will fall to the fitted regression line. Theoretically, if a model could explain $100 \%$ of the variance, the fitted values would always equal the observed values and, therefore, all the data points would fall on the fitted regression line. It can be observed that the sum of squared residuals $\left(\mathrm{R}^{2}\right)$ for all three output parameters are close to 1 that accounts for $100 \%$ of the variance. Hence it can be proved that neural network predictions are close to FEM results.

Table 5. New model cases for validation.

\begin{tabular}{ccccc}
\hline \multirow{2}{*}{ Sr. No. } & \multicolumn{3}{c}{ New Cases } \\
\cline { 2 - 5 } & Edge Dimension (mm) & Hole Dia. (mm) & Thickness of Plate (mm) & Pressure Applied (MPa) \\
\hline A & 900 & 80 & 15 & 0.35 \\
B & 600 & 60 & 25 & 0.4 \\
C & 700 & 70 & 20 & 0.45 \\
D & 800 & 90 & 25 & 0.5 \\
\hline
\end{tabular}

Table 6. Validation of results.

\begin{tabular}{|c|c|c|c|c|c|c|c|c|c|c|}
\hline \multirow{2}{*}{ Sr. No. } & \multirow{2}{*}{ Model } & \multicolumn{3}{|c|}{$\begin{array}{c}\text { Maximum Equivalent von Mises } \\
\text { Stress }\end{array}$} & \multicolumn{3}{|c|}{$\begin{array}{c}\text { Maximum Equivalent von Mises } \\
\text { Strain }\end{array}$} & \multicolumn{3}{|c|}{$\begin{array}{c}\text { Directional Deformation in }(-Z) \\
\text { Direction }\end{array}$} \\
\hline & & ANN & ANSYS & $\%$ & ANN & ANSYS & $\%$ & ANN & ANSYS & $\%$ \\
\hline 1 & A & 114.28 & 117.00 & 2.32 & 0.00065 & 0.00059 & 9.25 & 0.63140 & 0.66198 & 4.62 \\
\hline 2 & B & 22.79 & 21.85 & 4.31 & 0.00011 & 0.00011 & 1.59 & 0.03625 & 0.03450 & 5.08 \\
\hline 3 & $\mathrm{C}$ & 51.25 & 49.22 & 4.11 & 0.00024 & 0.00025 & 2.07 & 0.14082 & 0.13491 & 4.38 \\
\hline 4 & $\mathrm{D}$ & 47.74 & 45.62 & 4.66 & 0.00024 & 0.00023 & 3.89 & 0.13281 & 0.13041 & 1.84 \\
\hline
\end{tabular}

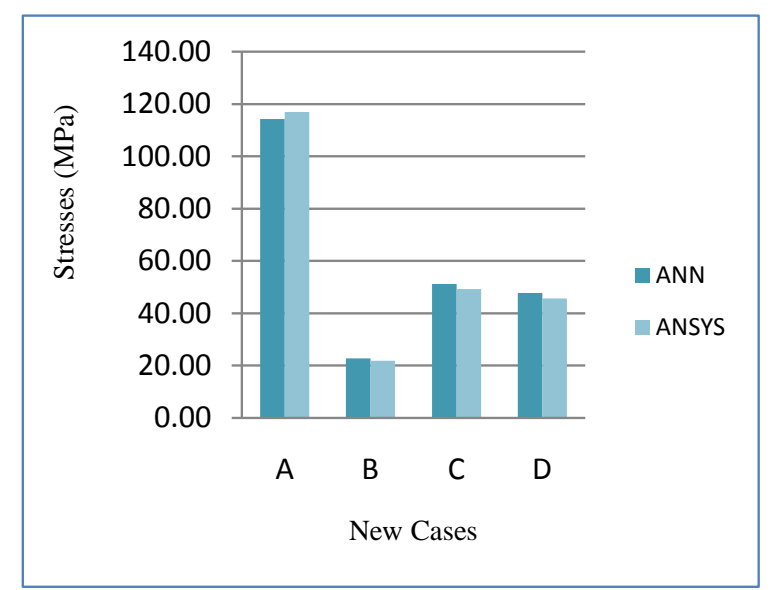

Figure 4. Max. equivalent von Mises stress by ANN and ANSYS for model case 1. 


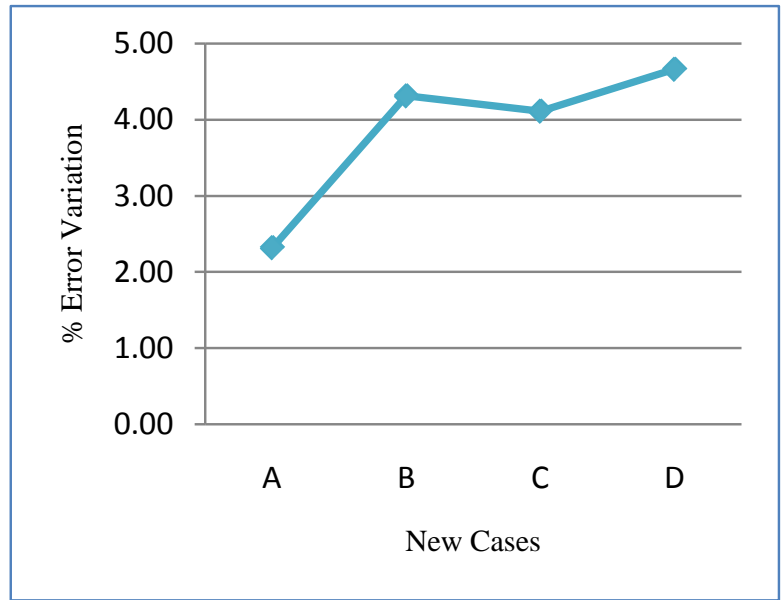

Figure 5. \% Variation of max. equivalent stress for ANN and ANSYS for model case 1.

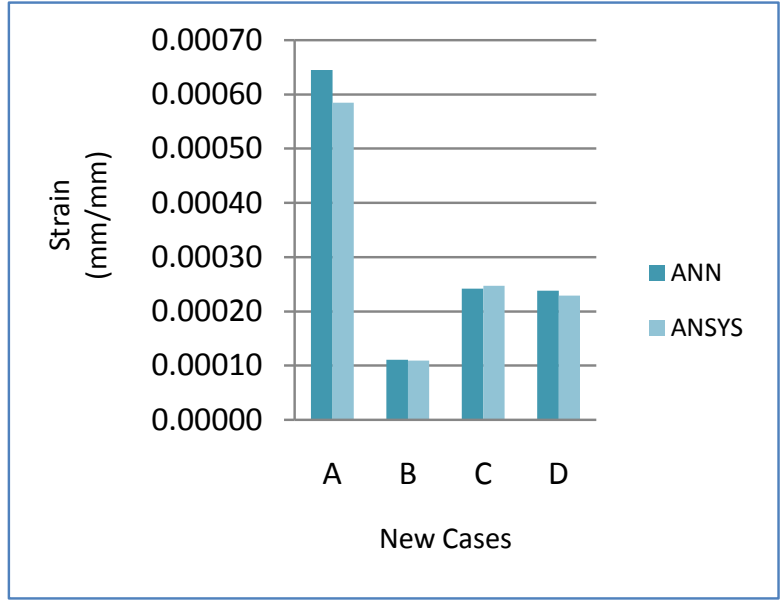

Figure 6. Max. equivalent von Mises strain by ANN and ANSYS for model case 2.

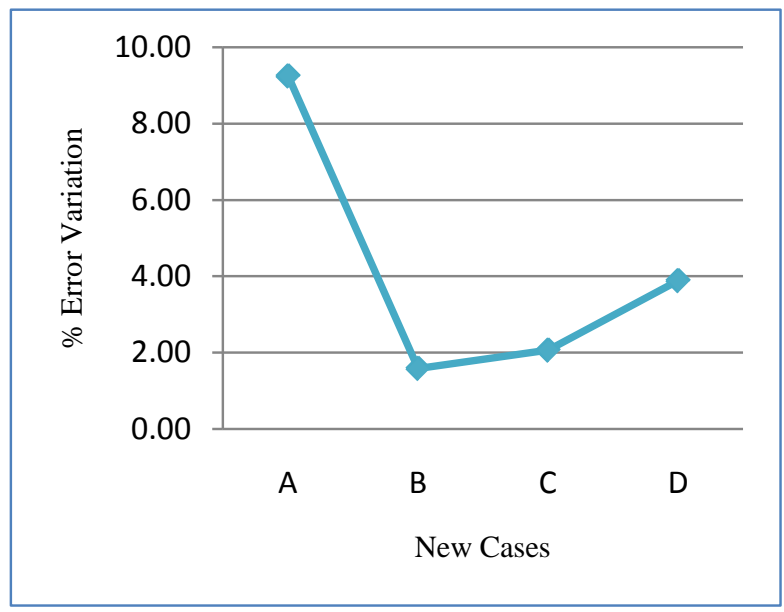

Figure 7. \% Variation of max. equivalent strain for ANN and ANSYS for model case 2. 


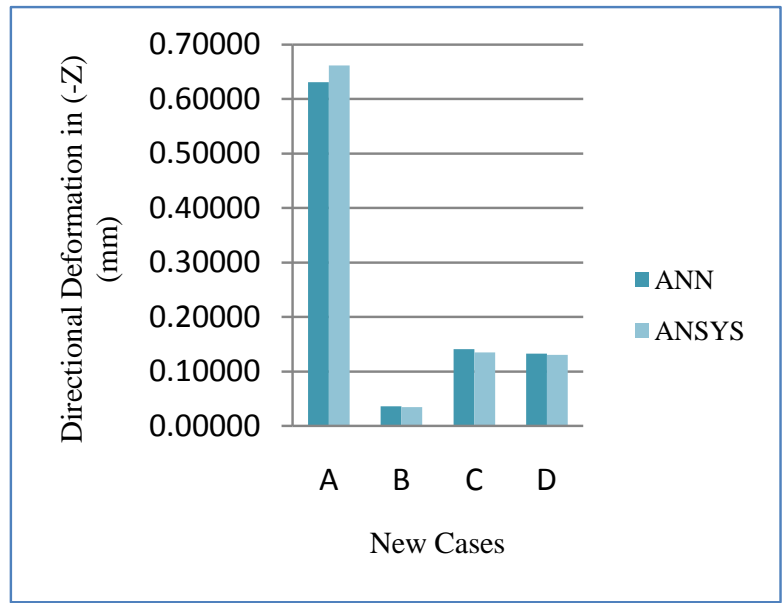

Figure 8. Directional deformation in -Z direction by ANN and ANSYS for model case.

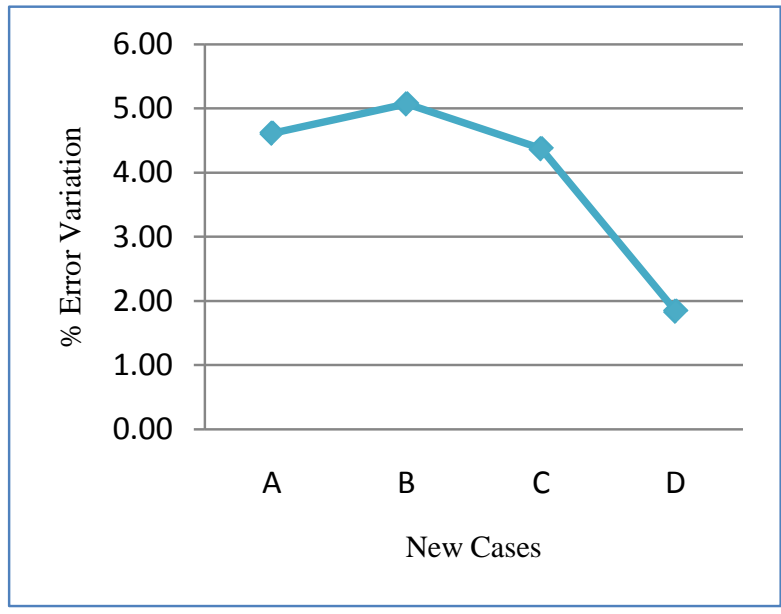

Figure 9. \% Variation of directional deformation in $-\mathrm{Z}$ direction of ANN and ANSYS for model case 3.

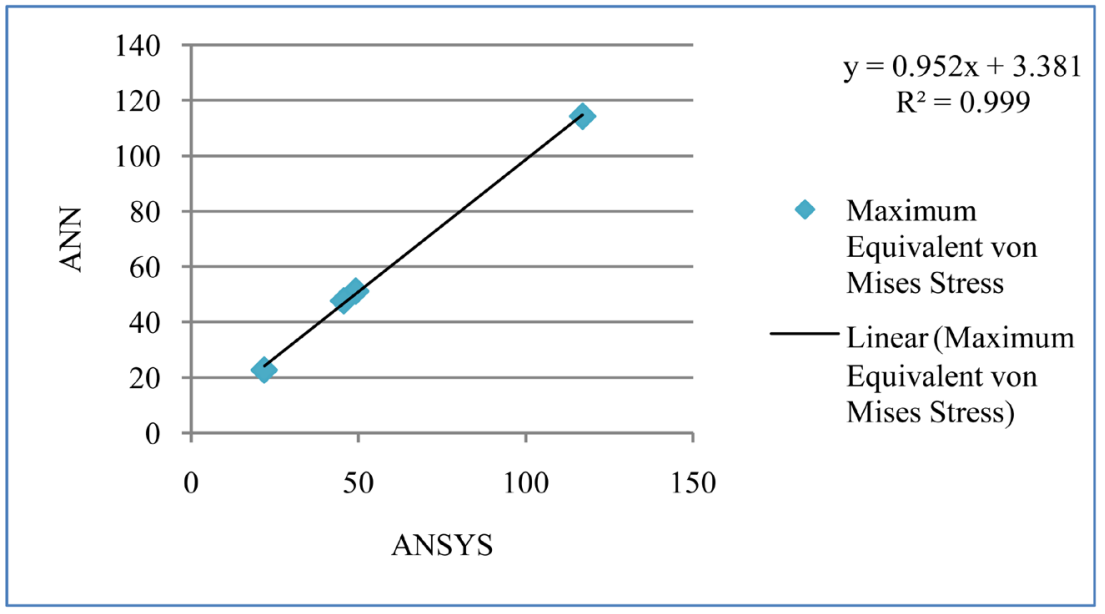

Figure 10. Regression analyses for max. equivalent von Mises stress between ANN and ANSYS for new models. 


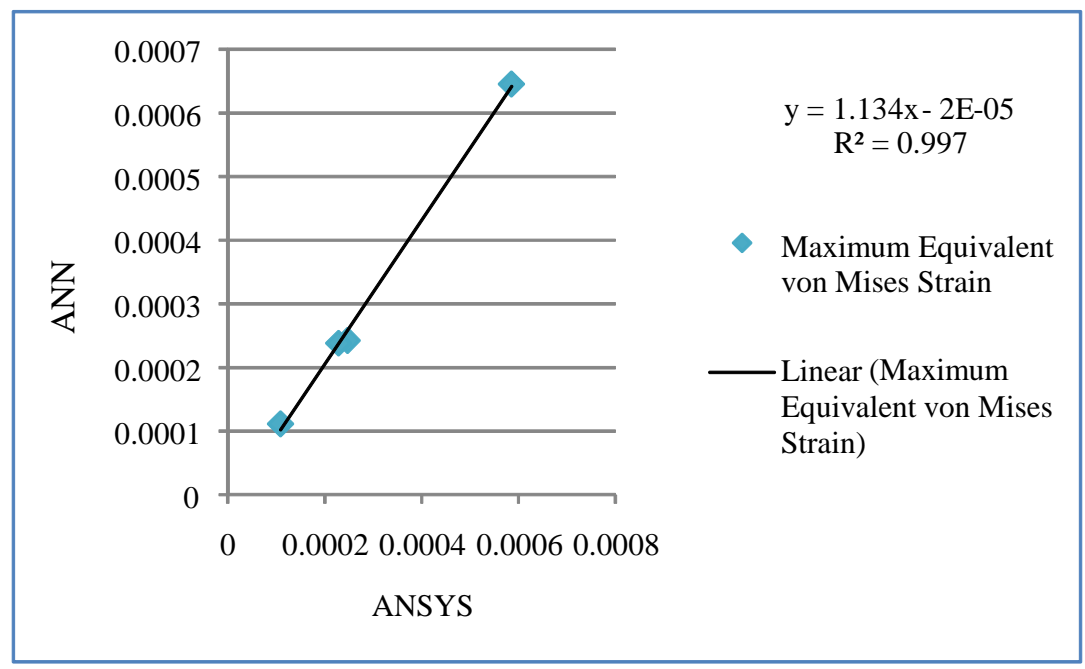

Figure 11. Regression analyses for Max. equivalent von Mises strain between ANN and ANSYS for new models.

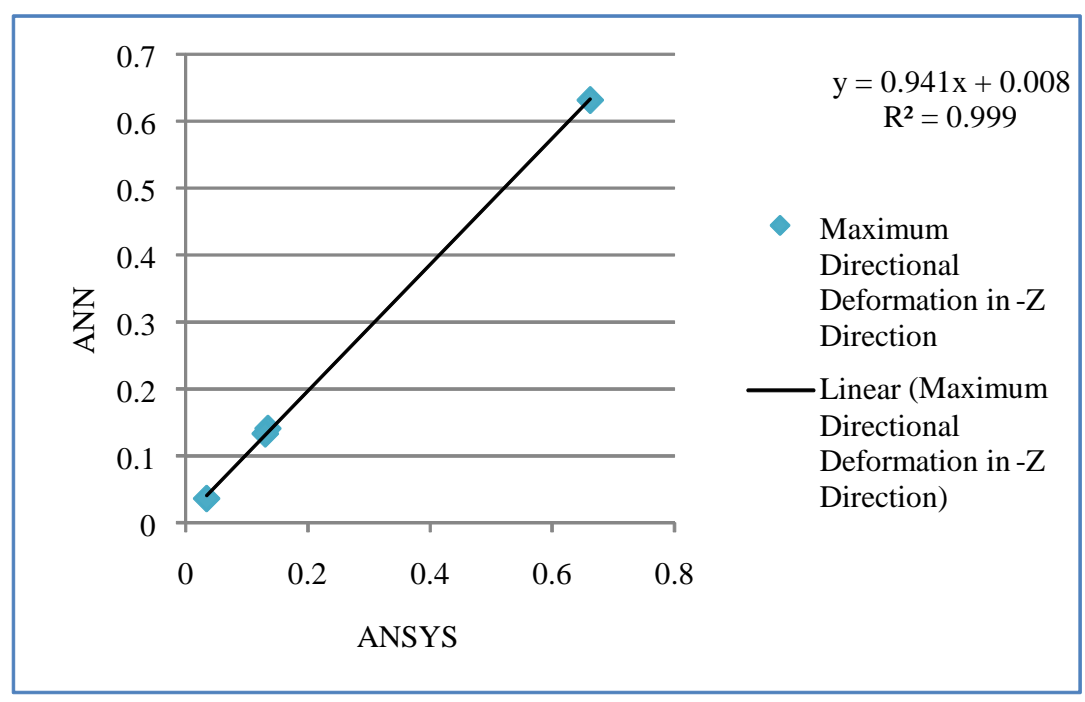

Figure 12. Regression analyses for directional deformation in -Z direction between ANN and ANSYS for new models.

\section{Conclusions}

Followings are the salient conclusions of this study:

1) Artificial Neural Network (ANN) is a very powerful tool for stress analysis of triangular plates with concentric cut-outs.

2) Artificial Neural Network approach is easy and fast whereas traditional techniques are tedious and time consuming and require greater skills.

3) The differences between the maximum equivalent von Mises stress, strain and directional deformation calculated by ANN and ANSYS Workbench 15.0 are low.

4) Using ANN, dependency upon costly analysis and design packages can be avoided.

\section{References}

[1] McCulloch, W.S. and Pitts, W.H. (1943) A Logical Calculus of the Ideas Imminent in Nervous Activity. The Bulletin of Mathematical Biophysics, 5, 115-133. http://dx.doi.org/10.1007/BF02478259 
[2] Garrett, J.H. (1994) Where and Why Artificial Neural Networks Are Applicable in Civil Engineering. Journal of Computing in Civil Engineering, 8, 129-130. http://dx.doi.org/10.1061/(ASCE)0887-3801(1994)8:2(129)

[3] Nicholas, P.E., Padmanaban, K.P., Vasudevan, D. and Selvaraj, I.J. (2014) Neural Network Based Buckling Strength Prediction of Laminated Composite Plate with Central Cutout. Applied Mechanics and Materials, 592-594, 560-564. http://dx.doi.org/10.4028/www.scientific.net/AMM.592-594.560

[4] Adeli, H. (2001) Neural Networks in Civil Engineering: 1989-2000. Computer-Aided Civil and Infrastructure Engineering, 16, 126-142. http://dx.doi.org/10.1111/0885-9507.00219

[5] ANSYS (2013) Workbench User’ s Guide. ANSYS Work. 15.0 15317, 724-746.

[6] Pan, Z., Cheng, Y. and Liu, J. (2013) Stress Analysis of a Finite Plate with a Rectangular Hole Subjected to Uniaxial Tension Using Modified Stress Functions. International Journal of Mechanical Sciences, 75, 265-277. http://dx.doi.org/10.1016/j.ijmecsci.2013.06.014

[7] Paik, J.K. (2008) Ultimate Strength of Perforated Steel Plates under Combined Biaxial Compression and Edge Shear Loads. Thin-Walled Structures, 46, 207-213. http://dx.doi.org/10.1016/j.tws.2007.07.010

[8] Baba, B.O. (2007) Buckling Behavior of Laminated Composite Plates. Journal of Reinforced Plastics and Composites, 26, 1637-1655. http://dx.doi.org/10.1177/0731684407079515

[9] Singh, A. and Paul, U. (2003) Finite Displacement Static Analysis of Thin Plate with an Opening-A Variational Approach. International Journal of Solids and Structures, 40, 4135-4151. http://dx.doi.org/10.1016/S0020-7683(03)00204-X

[10] Wu, H.C. and Mu, B. (2003) On Stress Concentrations for Isotropic/Orthotropic Plates and Cylinders with a Circular Hole. Composites Part B: Engineering, 34, 127-134. http://dx.doi.org/10.1016/S1359-8368(02)00097-5

[11] Ukadgaonker, V.G. and Rao, D.K.N. (2000) A General Solution for Moments around Holes in Symmetric Laminates. Composite Structures, 49, 41-54. http://dx.doi.org/10.1016/S0263-8223(99)00124-5

[12] Hu, H.-T. and Lin, B.-H. (1995) Buckling Optimization of Symmetrically Laminated Plates with Various Geometries and End Conditions. Composites Science and Technology, 55, 277-285.

http://dx.doi.org/10.1016/0266-3538(95)00105-0 